\title{
Downregulation of peroxiredoxin-1 by $\beta$-elemene enhances the radiosensitivity of lung adenocarcinoma xenografts
}

\author{
GUOQUAN LI ${ }^{1}$, BINGBING XIE ${ }^{1}$, XIAOLONG LI ${ }^{2}$, YINGHAI CHEN ${ }^{1}$, \\ YINGHUI XU ${ }^{3}$, MENG XU-WELLIVER ${ }^{4}$ and LIJUAN ZOU ${ }^{1}$ \\ ${ }^{1}$ Department of Radiation Oncology, Second Affiliated Hospital of Dalian Medical University, Dalian, Liaoning 116027; \\ ${ }^{2}$ Radiation Oncology Center, People's Liberation Army No. 323 Hospital, Xi'an, Shanxi 710000; ${ }^{3}$ Department of \\ Neurosurgery, First Affiliated Hospital of Dalian Medical University, Dalian, Liaoning 116001, P.R. China; \\ ${ }^{4}$ Department of Radiation Oncology, Ohio State University, Columbus, OH 43210-1219, USA
}

Received November 20, 2014; Accepted December 23, 2014

DOI: $10.3892 /$ or.2015.3732

\begin{abstract}
. $\beta$-elemene, the active component of elemene (1-methyl-1-vinyl-2,4-diisopropenyl-cyclohexane), is a naturally occurring compound isolated from the traditional Chinese medicinal herb Curcuma wenyujin. Studies have confirmed that $\beta$-elemene enhances the radiosensitivity of lung cancer cell lines such as A549, by multiple pathways; however, their underlying mechanisms and pathways are yet to be elucidated. In the present study, two-dimensional differential in-gel electrophoresis and matrix-assisted laser desorption/ionization time-of-flight tandem mass spectrometry were used to profile the different proteins in A549 cell xenograft models of both treatment groups. The protein/mRNA expression was assessed by reverse transcription-polymerase chain reaction and western blotting techniques in tumor samples from all treatment groups. As a critical player in redox regulation of cancer cells, inhibition of peroxiredoxin-1 (Prx-1) may be an effective option for enhancing the tumor response to radiation. We further verified Prx-1 expression at the transcription and translation levels. $\beta$-elemene at a dose of $45 \mathrm{mg} / \mathrm{kg}$ had little effect on the Prx-1 protein expression, which was correlated with a moderate antitumor effect. However, a $45 \mathrm{mg} / \mathrm{kg}$ dose of $\beta$-elemene significantly inhibited the Prx-1 mRNA expression, thereby suggesting a possible influence on the transcriptional process, and radiation significantly increased the Prx-1 mRNA/protein expression compared to the control group $(\mathrm{p}<0.01)$. Notably, Prx-1 mRNA/protein expression was significantly lower in the $\beta$-elemene/radiation co-treatment group compared to the baseline levels in the control group $(\mathrm{p}<0.01)$. These results suggest that radiation-induced Prx-1 expression is directly or
\end{abstract}

Correspondence to: Dr Lijuan Zou, Department of Radiation Oncology, Second Affiliated Hospital of Dalian Medical University, Dalian, Liaoning 116027, P.R. China

E-mail: lgqjym@163.com

Key words: lung cancer, radiosensitivity, $\beta$-elemene, peroxiredoxin-1 indirectly suppressed by $\beta$-elemene, thus suggesting a new pathway by which to reverse radioresistance.

\section{Introduction}

Lung cancer is the most prevalent cancer found in both men and women and is the leading cause of cancer-related death worldwide (1). Radiotherapy and chemotherapy have been the major options in the treatment of locally advanced lung cancer. Radiotherapy mainly aims at local tumor control, while chemotherapy reduces the risk of distant metastasis. Despite recent advances in radiotherapy (image guidance, adaptive treatment planning, hyperfractionation or hypofractionation, dose escalation), and the discoveries of novel chemotherapy and targeted agents, the prognosis for 5-year survival in patients with locally advanced lung cancer is still poor $(\sim 15-$ $25 \%$ ) (1). One of the factors contributing to treatment failure is local recurrence, which is believed to stem from radiation resistance by cancer cells. Identifying agents that overcome radiation resistance is a promising strategy by which to enhance the effect of radiation. $\beta$-elemene is the active component of elemene (1-methyl-1-vinyl-2,4-diisopropenyl-cyclohexane), a naturally occurring compound that is isolated from the traditional Chinese medicinal herb Curcuma wenyujin. A number of studies have confirmed that this agent enhances the radiosensitivity of human cancer cell lines (2-4), as well as rabbit VX2 carcinoma (5). Some in vitro studies have attributed the enhanced radiation response to increased apoptosis and cell cycle arrest in the $\mathrm{G} 2 / \mathrm{M}$ phase $(2,3,6,7)$. Our previous studies found that $\beta$-elemene radiosensitized the lung cancer A549 cell line by enhancing DNA damage and inhibiting DNA repair (8), as well as decreased radiation-induced expression of survivin and HIF-1 $\alpha$ in an A549 cell xenograft model (9). Thus it is clear that $\beta$-elemene enhances the response to radiation through multiple pathways; however, the underlying mechanisms remain to be elucidated and potential novel pathways are still to be unveiled.

It is well known that radiation increases the level of intracellular reactive oxygen species (ROS), mainly $\mathrm{H}_{2} \mathrm{O}_{2}$, and evokes a series of intracellular biochemical events including DNA mutation and DNA damage, which lead to cell cycle arrest 
and apoptosis $(10,11)$. Upregulation of antioxidant capacity due to intrinsic oxidative stress in cancer cells was thought to confer radioresistance; therefore, targeted redox modulation has been suggested as a promising novel approach in cancer therapy (12). Peroxiredoxin-1 (Prx-1) is a critical member among the Prx family, and is a major $\mathrm{H}_{2} \mathrm{O}_{2}$ scavenger and signaling regulator. Phosphorylation of Prx-1 allows localized $\mathrm{H}_{2} \mathrm{O}_{2}$ accumulation for cell signaling (13). As a critical player in redox regulation in cancer cells, inhibition of Prx-1 may be an effective way to enhance tumor radioresponse. However, it has not been confirmed whether $\beta$-elemene inhibits Prx- 1 for enhancing a radioresponse.

Currently, proteomics concerning comprehensive protein profile changes caused by multi-gene alterations is considered to be an effective tool for studying the mechanisms of disease, and for finding potential biomarkers and new therapeutic targets. The main objective of the present study was to discover new molecular targets with enhancement of radiosensitivity by $\beta$-elemene, in lung adenocarcinoma xenografts. This was achieved using two-dimensional differential in-gel electrophoresis (2D-DIGE) and matrix-assisted laser desorption/ionization time-of-flight tandem mass spectrometry. Reverse transcription-polymerase chain reaction (RT-PCR) and western blotting techniques were used to confirm the findings of the 2D-DIGE analysis. Our analysis revealed that $\beta$-elemene directly or indirectly inhibited Prx-1 expression to enhance tumor radiosensitivity.

\section{Materials and methods}

Chemicals and cell culture. $\beta$-elemene was purchased from Jingang Pharmaceutical Co. (Dalian, China). The human lung adenocarcinoma cell line A549 was purchased from the Cell Center of the Chinese Academy of Medical Sciences. Cells were grown in Rosewell Park Memorial Institute (RPMI)-1640 medium (Gibco-BRL/Invitrogen, Carlsbad, CA, USA), supplemented with $10 \%$ fetal bovine serum (TBD Bio, Tianjin, China) at $37^{\circ} \mathrm{C}$ in a humidified atmosphere with $5 \% \mathrm{CO}_{2}$.

Animals and tumor models. Female athymic BALB/c nu/nu mice aged 6-8 weeks were purchased from the Animal Experiment Center of Dalian Medical University and maintained under specific pathogen-free (SPF) conditions. The facilities and the protocol for these experiments were consistent with the regulations of animal use for biomedical experiments as issued by the Ministry of Science and Technology of China, and approved by the Animal Care Committee of Dalian Medical University. A549 cells were subcutaneously injected into the right hind leg $\left(1 \times 10^{7}\right.$ cells/animal). The tumor sizes were measured every two days using vernier calipers. At 4-5 weeks, tumor volumes reached the required size $\left(0.8-1.0 \mathrm{~cm}^{3}\right)$. Tumor volumes were calculated using the following formula: $(0.5 \mathrm{x}$ largest diameter $\mathrm{x}$ smallest diameter $^{2}$ ) as previously reported (9).

Xenograft treatment with radiation andlor $\beta$-elemene. For radiation treatment, the mice were placed in a specially designed polyvinylchloride box, and the right hind legs bearing the xenograft tumors were exposed out of the box. The mice were immobilized and tumors were positioned in the center of a $4 \times 3 \mathrm{~cm}$ radiation field, with the rest of the body remaining outside of the radiation field. Radiation was delivered with $6 \mathrm{MeV}$ electron beams from a linear accelerator (Varian) at a single dose of $5 \mathrm{~Gy}$. For drug alone treatment, a single dose of $45 \mathrm{mg} / \mathrm{kg}$ of $\beta$-elemene was injected intraperitoneally. For drug and radiation combined treatment, radiation was delivered $1 \mathrm{~h}$ after $\beta$-elemene was injected. For the control group, $0.9 \%$ sodium chloride $(\mathrm{NaCl})$ was injected intraperitoneally and the volume was the same as $45 \mathrm{mg} / \mathrm{kg}$ of $\beta$-elemene. The procedure was performed as previously reported (9).

Sample preparation for electrophoresis. Nude mice with tumors of $0.8-1.0 \mathrm{~cm}^{3}$ were divided into 2 groups ( 3 mice/group): radiation alone and combined treatment $(\beta$-elemene + radiation). The mice were sacrificed $24 \mathrm{~h}$ after treatment (9) and the tumors (three from each group) were excised and ground into powder in liquid nitrogen with a precooled mortar and pestle. Samples were then homogenized using a glass homogenizer on ice in $1 \mathrm{ml}$ of lysis buffer containing $7 \mathrm{M}$ urea, $2 \mathrm{M}$ thiourea, $4 \%$ CHAPS, $30 \mathrm{mM}$ Tris- $\mathrm{HCl}$ and $2 \%$ (v/v) protease inhibitor (Roche Diagnostics, Mannheim, Germany). After sonication on ice for $10 \mathrm{sec}$ using an ultrasonic processor, the samples were centrifuged for $30 \mathrm{~min}$ at $12,000 \mathrm{rpm}$ to remove particulate materials. The supernatant was collected and the protein concentration was determined using a Protein Assay kit (Bio-Rad, Hercules, CA, USA). Proteins from six samples were stored at $-80^{\circ} \mathrm{C}$ for future use.

Two-dimensional differential in-gel electrophoresis and imaging. The $\mathrm{pH}$ of the lysate was adjusted to 8.0-9.0 with $50 \mathrm{mM} \mathrm{NaOH}$, and the concentration was adjusted to $5 \mathrm{mg} / \mathrm{ml}$ with lysis buffer. Equal amounts of proteins from the six samples were pooled together as the internal standard. According to the statistical principle, $50 \mu \mathrm{g}$ of proteins taken from every group were labeled with 400 pmol of Cy 3 or Cy5 respectively, whereas $50 \mu \mathrm{g}$ of internal standards were labeled with $400 \mathrm{pmol}$ of Cy2. Combined samples $(150 \mu \mathrm{g})$ were then diluted with rehydration buffer and the total volume was made up to $450 \mu \mathrm{l}$. The combined samples were loaded on a $\mathrm{pH}$ gradient strip for isoelectric focusing (IEF) on an Ettan IPGphor system (Amersham Biosciences, Uppsala, Sweden): $500 \mathrm{~V}$ for $1 \mathrm{~h} ; 1,000 \mathrm{~V}$ for $1 \mathrm{~h} ; 8,000 \mathrm{~V}$ for $8 \mathrm{~h}$; $500 \mathrm{~V}$ for $4 \mathrm{~h}$. After IEF, the strips were equilibrated twice and transferred onto $12 \%$ vertical polyacrylamide gels cast in low fluorescence glass plates using a Hoefer SE600 system (GE Healthcare, Uppsala, Sweden). Electrophoresis was conducted until the bromophenol blue front reached the bottom of the gels. The gels were scanned on a Typhoon 9410 scanner (Amersham Biosciences) using excitation/emission wavelengths specific for Cy2 (488/520 nm), Сy3 (532/580 nm) and Cy5 (633/670 nm), respectively (Fig. 1). Intragel spot detection and quantification, as well as intergel matching and quantification were performed using Differential In-gel Analysis (DIA) and Biological Variation Analysis (BVA) modules of DeCyder software version 6.5 (Amersham Biosciences). The gel with the highest spot count was assigned as the master gel. In DIA, the $\mathrm{Cy} 2, \mathrm{Cy} 3$ and $\mathrm{Cy} 5$ images for each gel were merged, spot boundaries were automatically detected and normalized spot volumes (protein abundance) were calculated. The resulting spot maps were exported to BVA. Gel-to-gel matching of 

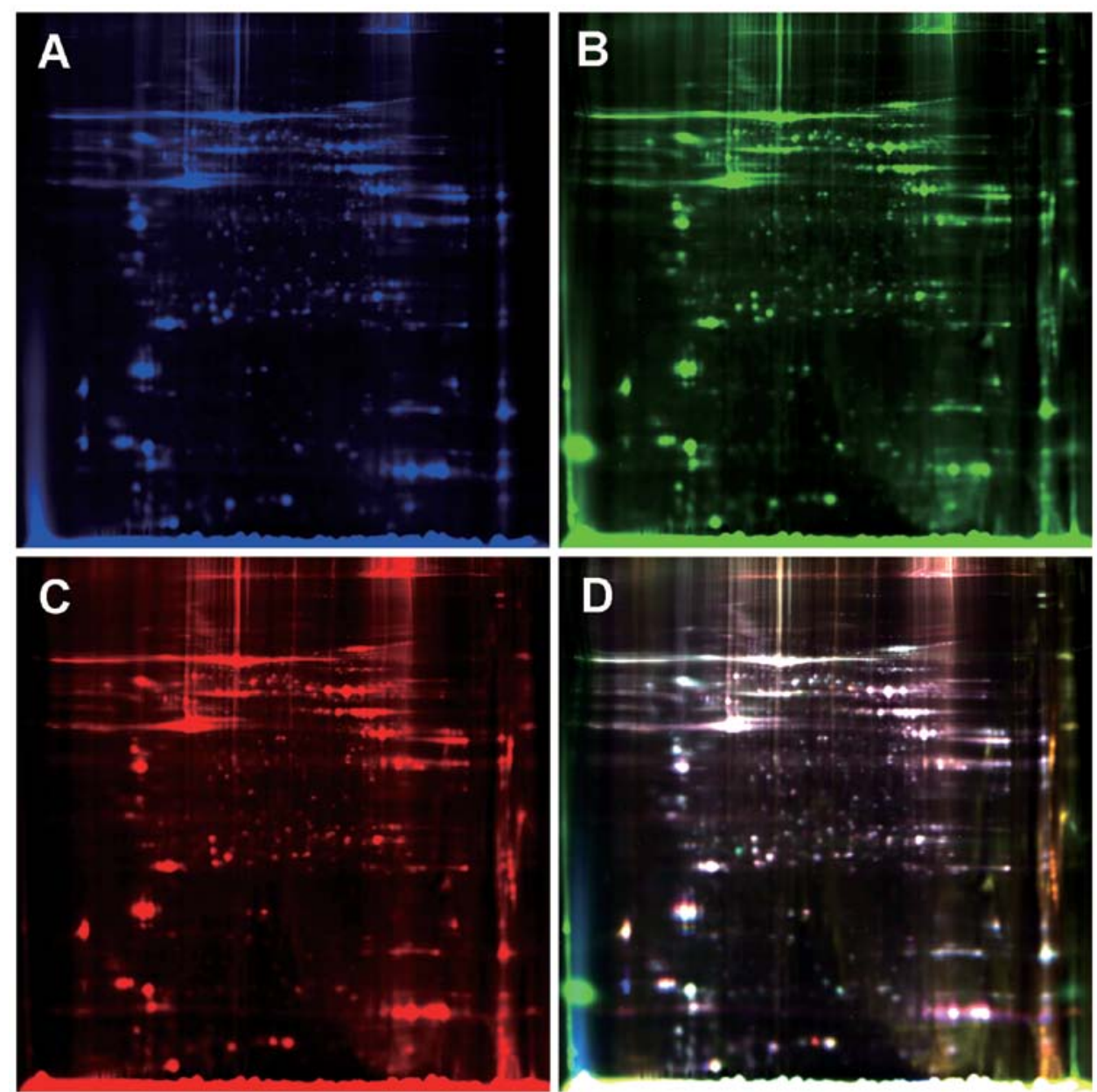

Figure 1. 2D-DIGE images were obtained with a scanner at three different excitation wavelengths: (A) Cy2-labeled image using excitation/emission wavelengths at 488/520 nm; (B) Cy3-labeled image at 532/580 nm; (C) Cy5-labeled image at 633/670 nm; (D) overlapped image. 2D-DIGE, two-dimensional differential in-gel electrophoresis.

the standard spot maps from each gel, followed by statistical analysis of protein abundance change between samples was performed in a BVA module. The standardized average spot volume ratios exceeding 1.2 were considered statistically significant (Student's t-test, $\mathrm{p}<0.05$ ).

Protein digestion and mass spectrometry. For mass spectrometric analysis, three preparative gels loaded with $1 \mathrm{mg}$ of protein were run under the same conditions and stained with Bio-Safe Colloidal Coomassie blue (Bio-Rad, San Francisco, CA, USA). Differentially expressed protein spots of interest were excised from both the DIGE analytic gels and preparative gels with the help of Ettan Spot Picker (GE Healthcare) and subjected to in-gel digestion with trypsin. Briefly, gel plugs were destained with $30 \%$ acetonitrile in $0.1 \mathrm{M}$ ammonium carbonate $\left(\mathrm{NH}_{4} \mathrm{HCO}_{3}\right)$ for $20 \mathrm{~min}$ and vacuum dried. Then, digestion buffer $\left(20 \mathrm{ng} / \mathrm{ml}\right.$ trypsin in $20 \mathrm{mM} \mathrm{NH}_{4} \mathrm{HCO}_{3}$ ) was added and the samples were digested at room temperature overnight. Peptides were extracted twice with a solution containing 50\% acetonitrile (ACN) and $0.1 \%$ trifluoroacetic acid (TFA). The extracted peptides were removed, dried and re-suspended in 50\% ACN and 0.1\% TFA. Equal volumes of sample and a-HCCA matrix $(5 \mathrm{mg} / \mathrm{ml})$ were spotted and mixed on the MALDI-TOF target plate. Peptide mixtures were analyzed with a 4800 Plus MALDI TOF/TOF ${ }^{\mathrm{TM}}$ Analyzer (Applied Biosystems, USA) in a positive ion reflector mode. The obtained peptide mass fingerprint spectra were analyzed by searching the non-redundant protein database of the National Center for Biotechnology Information.

Sample preparation for reverse transcription-PCR and western blot analysis. Nude mice with tumors of $0.8-1.0 \mathrm{~cm}^{3}$ were randomized to four groups (5 mice/group), that included a control group and three treatment groups: $\beta$-elemene alone, radiation alone and $\beta$-elemene combined with radiation. The mice were sacrificed and the tumors were excised and cut into small pieces.

Reverse transcription-PCR analysis. Total RNA from the tumor tissues was isolated using TRIzol reagent (Invitrogen, Carlsbad, CA, USA) according to the manufacturer's instructions. The reverse transcription-PCR analysis was performed using a RT-PCR kit (Takara, Otsu, Japan). The specific primer sequences were as follows: Prx-1 (forward primer, 5'-ATGTC TTCAGGAAATGCTAAAAT-3' and reverse primer, 5'-TCAC TTCTGCTTGGAGAAATATTC-3'); and $\beta$-actin (forward primer, 5'-CAAGAGATGGCCACGGCTGCT-3' and reverse primer, 5'-TCCTTCTGCATCCTGTCGGCA-3'). The PCR 


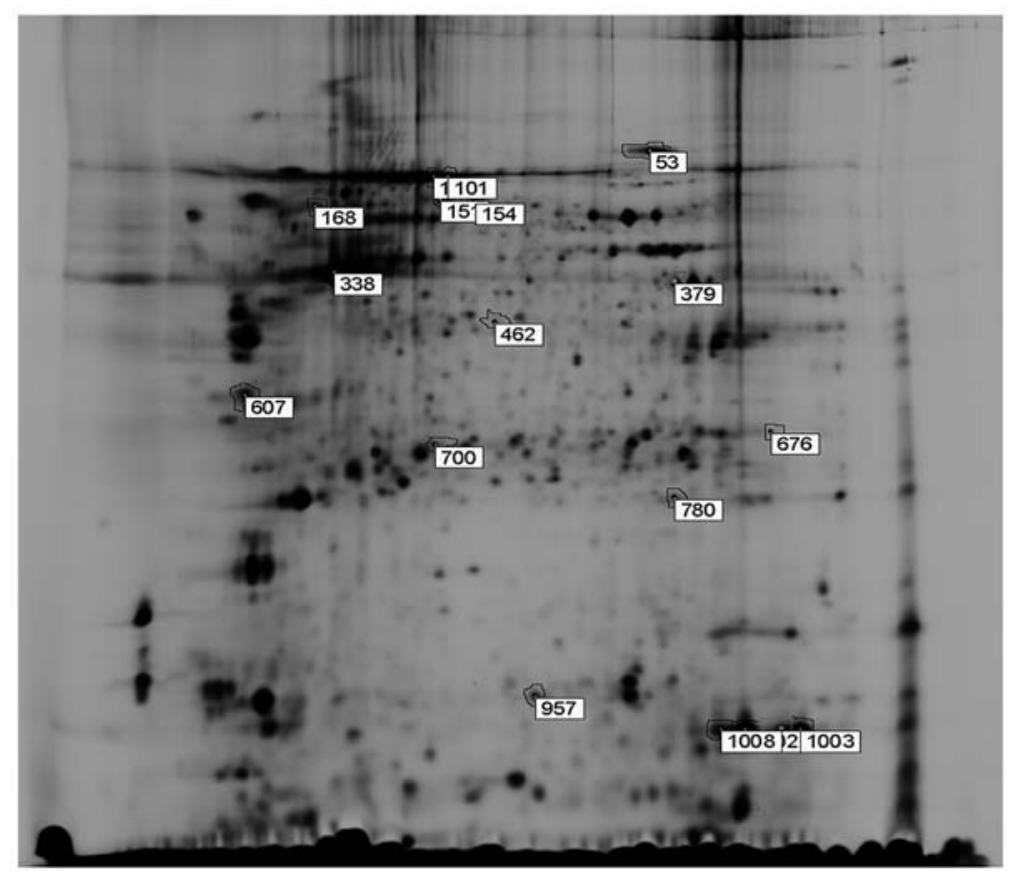

Figure 2. The different 17 protein spots were identified by DeCyder Differential Analysis software between the radiation and combined treatment group. The standardized average spot volume ratios that exceeded 1.2 were considered statistically significant (Student's t-test, $\mathrm{p}<0.05$ ).

protocol was as follows: initial denaturation at $94^{\circ} \mathrm{C}$ for $2 \mathrm{~min}$, followed by 35 cycles at $94^{\circ} \mathrm{C}$ for $30 \mathrm{sec}$, annealing at $59^{\circ} \mathrm{C}$, and extension at $72^{\circ} \mathrm{C}$ for $1 \mathrm{~min}$. The final extension was performed by an incubation step at $72^{\circ} \mathrm{C}$ for $7 \mathrm{~min}$. The PCR products were subjected to electrophoresis on agarose gel and visualized with ethidium bromide. The bands were analyzed with Quantity One software (Bio-Rad).

Western blot analysis. The tumor pieces were mixed in RIPA buffer and homogenized with polytron. Protein concentrations from tumor lysates were determined by Bio-Rad assays. Equal amounts of proteins were separated on SDS-10\% PAGE, transferred to polyvinylidene difluoride membrane, and probed with the indicated rabbit anti-Prx-1 polyclonal antibody (Lab Frontier, Korea) at a 1:1,000 dilution. This was followed by polyclonal goat anti-rabbit IgG antibody conjugated with horseradish peroxidase at a 1:2,000 dilution (Abcam, UK). The protein bands were detected by LabWorks software (UVP, Upland, CA, USA).

Statistical analysis. Statistical analyses were performed with the two-tailed Student's t-test or analysis of variance (ANOVA) to compare the experimental groups. Differences were considered significant when $p$-values were $\leq 0.05$. Results are expressed as mean $\pm \mathrm{SD}$ as indicated. All calculations were performed using SPSS version 11.0 (SPSS, Inc., Chicago, IL, USA).

\section{Results}

Analysis of 2-DE images. Results of the gel images were analyzed by DeCyder Differential Analysis software and a total number of 17 significantly differentiated spots were found between the radiation and the combined treatment
Table I. The confidence level and difference degree of the 17 differentiated protein spots (radiation/combined group).

\begin{tabular}{cccc}
\hline & \multicolumn{2}{c}{$\begin{array}{c}\text { Differentiated protein spots } \\
\text { (radiation/ combined group) }\end{array}$} & \\
\cline { 2 - 3 } Pos & Master no. & t-test & $\begin{array}{c}\text { Average } \\
\text { ratio }\end{array}$ \\
\hline 1 & 1002 & 0.0043 & 3.75 \\
2 & 1003 & 0.0039 & 3.23 \\
3 & 1008 & 0.0033 & 2.62 \\
4 & 379 & 0.012 & 1.46 \\
5 & 676 & 0.0053 & 1.33 \\
6 & 338 & 0.0089 & 1.26 \\
7 & 780 & 0.042 & 1.22 \\
8 & 462 & 0.0061 & 1.21 \\
9 & 151 & 0.025 & -1.20 \\
10 & 700 & 0.0075 & -1.21 \\
11 & 168 & 0.0041 & -1.22 \\
12 & 607 & 0.027 & -1.31 \\
13 & 53 & 0.034 & -1.48 \\
14 & 154 & 0.00081 & -1.49 \\
15 & 100 & 0.0018 & -1.54 \\
16 & 101 & 0.026 & -1.55 \\
17 & 957 & $8.9 \mathrm{e} 0-0.05$ & -1.90 \\
\hline
\end{tabular}

group (Fig. 2). Among the 17 spots, 8 spots represented proteins that were downregulated, whereas 9 spots were that of upregulated proteins in the combined group vs. radiation alone group. The confidence level and difference degree of 17 differentiated spots are shown in Table I. 
Table II. The results of peptide mass fingerprinting (PMF) of every differentially expressed protein spot.

\begin{tabular}{|c|c|c|c|c|c|c|c|c|}
\hline $\begin{array}{l}\text { Protein } \\
\text { ID }\end{array}$ & Protein name & Species & Accession no. & Mw & PI & Score & $\begin{array}{l}\text { Confidence } \\
\text { level }\end{array}$ & $\begin{array}{l}\text { Matched } \\
\text { peptide } \\
\text { fragments }\end{array}$ \\
\hline 53 & Serotransferrin & Mouse & gil21363012 & 78840.5 & 6.94 & 619 & 100 & 30 \\
\hline 168 & Unnamed protein product & Human & gil193787214 & 47061.7 & 4.94 & 290 & 100 & 23 \\
\hline 100 & Serum albumin precursor & Mouse & gil163310765 & 70700.5 & 5.75 & 846 & 100 & 18 \\
\hline 101 & Serum albumin precursor & Mouse & gil163310765 & 70700.5 & 5.75 & 1.100 & 100 & 24 \\
\hline 151 & $\begin{array}{l}\text { Chain A, TapasinERP57 } \\
\text { HETERODIMER }\end{array}$ & Human & gil220702506 & 54541.4 & 5.61 & 635 & 100 & 23 \\
\hline 154 & $\begin{array}{l}\text { Chain A, TapasinERP57 } \\
\text { HETERODIMER }\end{array}$ & Human & gil220702506 & 54541.4 & 5.61 & 573 & 100 & 23 \\
\hline 338 & Full-asctin, $\alpha$ skeletal muscle & Human & gil61218043 & 42366 & 5.23 & 770 & 100 & 12 \\
\hline 379 & Creatine kinase & Human & gil180588 & 43302 & 6.77 & 661 & 100 & 25 \\
\hline 607 & $\begin{array}{l}\text { Tropomyosin } \alpha-4 \text { chain } \\
\text { isoform } 2\end{array}$ & Human & gil4507651 & 28618.5 & 4.67 & 161 & 100 & 10 \\
\hline 462 & Unnamed protein product & Human & gil221040676 & 43022.8 & 4.99 & 103 & 99.997 & 7 \\
\hline 700 & Antioxidant enzyme AOE37-2 & Human & gil799381 & 30748.9 & 5.86 & 462 & 100 & 12 \\
\hline 676 & $\begin{array}{l}\text { Chain S, structure of the human } \\
\text { Mcadetf E } 165 \beta \text { a complex }\end{array}$ & Human & gil71042617 & 27996.2 & 8.57 & 342 & 100 & 11 \\
\hline 780 & Peroxiredoxin 1, isoform CRA_a & Human & gil119627386 & 22324.4 & 8.27 & 794 & 100 & 16 \\
\hline 957 & Transthyretin & Mouse & gil136465 & 15880 & 5.77 & 484 & 100 & 7 \\
\hline 1008 & $\begin{array}{l}\text { Chain B, crystal structure } \\
\text { of human hemoglobin A2 } \\
\text { (in R2 state) at } 2.2 \text { A resolution }\end{array}$ & Human & gil56553727 & 16028.3 & 7.97 & 170 & 100 & 4 \\
\hline 1002 & Chain B, deoxy hemoglobin & Human & gil27574242 & 16090.3 & 6.75 & 149 & 100 & 4 \\
\hline 1003 & $\begin{array}{l}\text { Chain A, deoxy Rhb1.1 } \\
\text { (recombinant hemoglobin) }\end{array}$ & Human & gil9256887 & 30418.8 & 8.91 & 184 & 100 & 4 \\
\hline
\end{tabular}

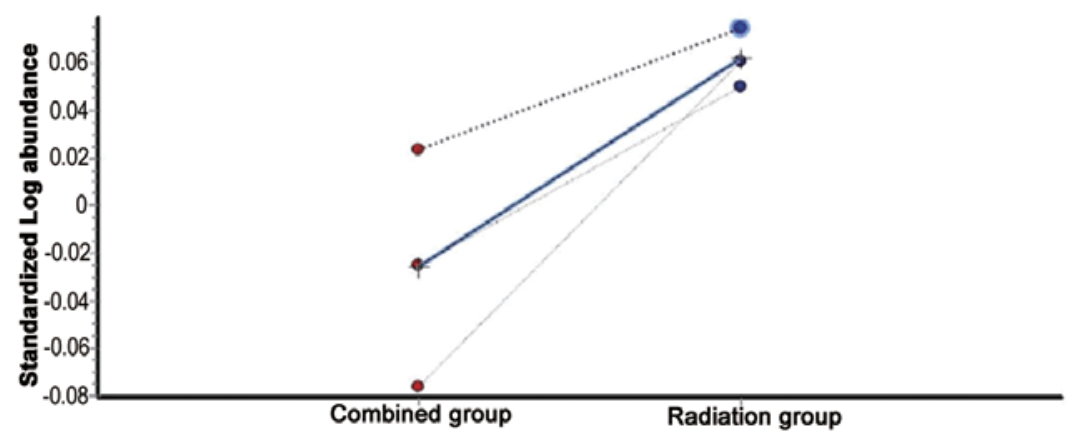

Figure 3. No.780 protein (peroxiredoxin-1) was downregulated in the combined treatment group compared with its level in the radiation group, when analyzed by mass spectrometry.

Analysis of the differentially expressed proteins by mass spectrometry. All 17 differentially expressed spots were selected for analysis by mass spectrometry. The peptide mass fingerprinting (PMF) of every protein was obtained by MALDI-TOF MS and the SWISS-PROT and the NCBI database search engine were used to identify these proteins (Table II). There were 13 proteins of human origin and 4 proteins of mouse origin. Among the identified human proteins, No. 780 protein called Prx-1, a radiation-related protein, was found to be downregulated in the combined treatment group (Fig. 3).
Expression of Prx-1 mRNA in each group. Prx-1 mRNA expression levels were investigated by RT-PCR in tumor samples in the control, $\beta$-elemene and radiation alone, and combined treatment groups (Fig. 4A). The levels of Prx-1 mRNA expression were compared and the results are shown in Fig. 4B. $\beta$-elemene alone at a dose of $45 \mathrm{mg} / \mathrm{kg}$ significantly inhibited the Prx-1 mRNA expression (2.12-fold lower) compared with the control group $(\mathrm{p}<0.01)$. However, radiation significantly increased the Prx-1 mRNA expression (1.36-fold higher) compared with the expression level in the control group 

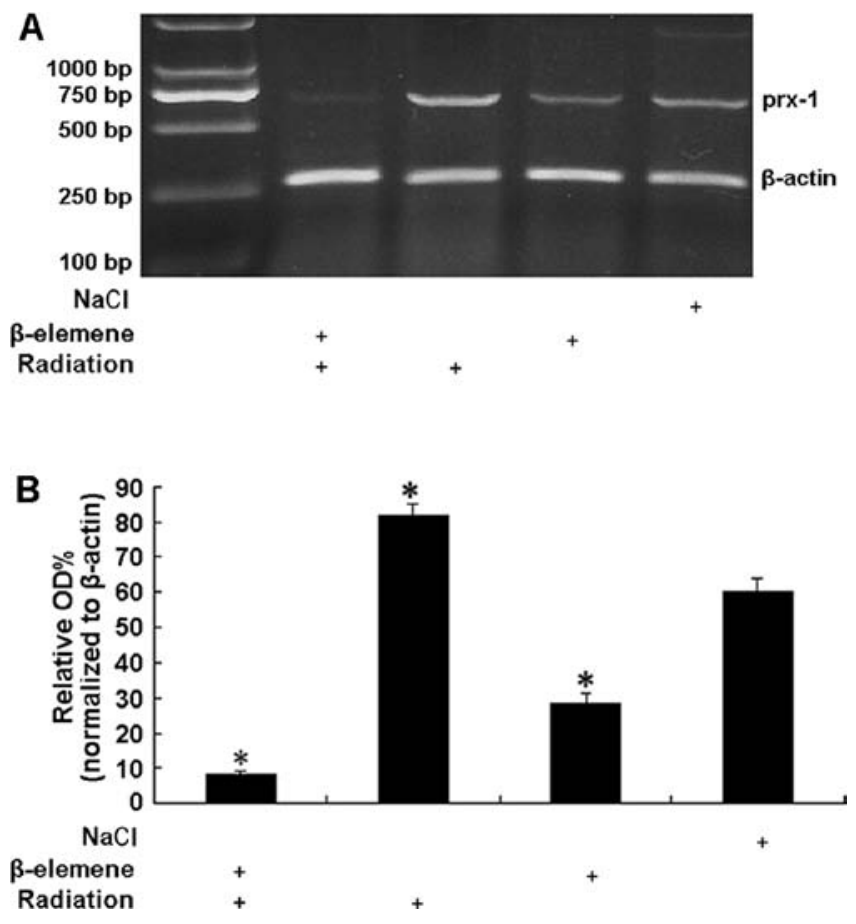

Figure 4. Prx-1 mRNA expression in the xenografts as analyzed by RT-PCR (A) Control $(\mathrm{NaCl}), \beta$-elemene at $45 \mathrm{mg} / \mathrm{kg}$, radiation at $5 \mathrm{~Gy}$, and combination of $\beta$-elemene and radiation were used in the experiment. (B) Prx-1 mRNA was amplified by RT-PCR and quantified by relative OD. The results represent the mean \pm SD of five mice in every group. The OD in the $\beta$-elemene or radiation group was compared with the control group; the OD in the combination group was compared with the other groups ( $\mathrm{p}<0.01)$. Prx-1, peroxiredoxin-1.
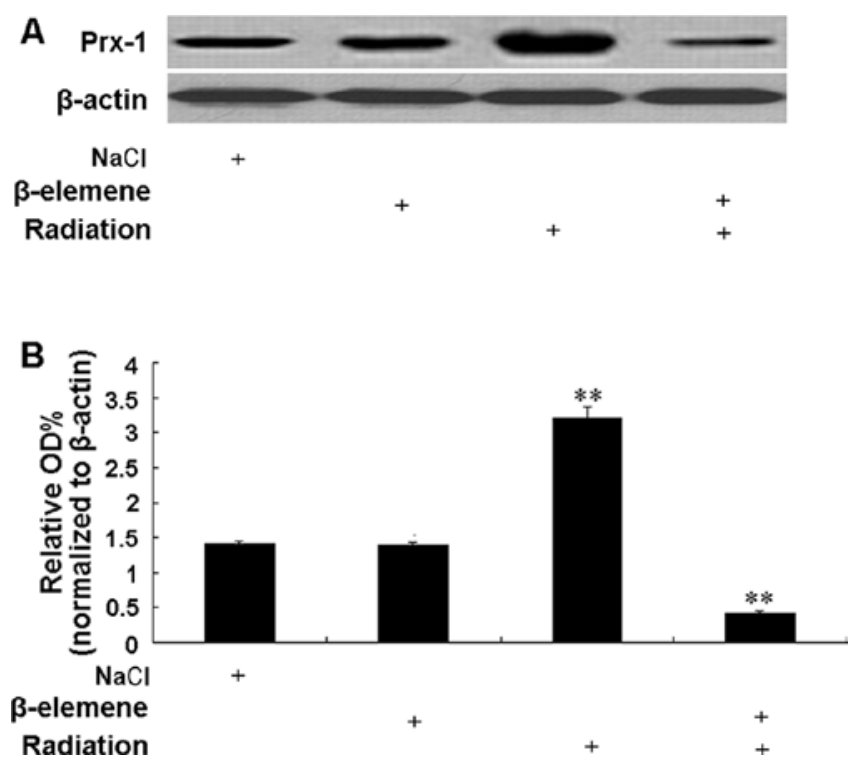

Figure 5. Prx-1 protein expression in the xenografts as analyzed by western blotting. (A) Control $(\mathrm{NaCl}), \beta$-elemene at $45 \mathrm{mg} / \mathrm{kg}$, radiation at $5 \mathrm{~Gy}$, and combination of $\beta$-elemene and radiation were used in the experiment. (B) Prx-1 protein levels from the western blot analyses were quantified by relative optical density (OD)\%. The OD in the treatment group was compared with the control group $\left({ }^{* *} \mathrm{p}<0.01\right)$.The results represent the mean \pm standard deviation (SD) of five mice in each treatment group. Prx-1, peroxiredoxin-1.

$(\mathrm{p}<0.01)$. Notably, Prx-1 mRNA expression was significantly decreased in the $\beta$-elemene/radiation co-treatment group (7.18-fold lower) compared with the basal expression in the control group $(\mathrm{p}<0.01)$.

Expression of Prx-1 protein in each group. Prx-1 protein expression levels were investigated by western blotting in tumor samples from the control, $\beta$-elemene and radiation alone and co-treatment groups (Fig. 5A). The level of Prx-1 protein expression was compared between the groups and the results are shown in Fig. 5B. $\beta$-elemene alone at the dose of $45 \mathrm{mg} / \mathrm{kg}$ had little effect on the Prx-1 protein expression compared with control group. However, radiation significantly increased the Prx-1 protein expression (2.29-fold higher) compared with the expression level in the control group $(\mathrm{p}<0.01)$. Notably, Prx-1 protein expression was significantly decreased (3.33-fold lower) in the $\beta$-elemene/radiation co-treatment group compared with the basal expression in the control group $(\mathrm{p}<0.01)$.

\section{Discussion}

2D-PAGE has become one of the most widely used methods in proteomics as the separation of a large number of proteins is necessary in complex biological samples (14). Compared to conventional 2D-PAGE, difference gel electrophoresis (DIGE)-based proteomics with fluorescence labeling has many advantages such as higher sensitivity, reproducibility and less technical variations due to a pooled control as internal standard (15-17). In the present study, we used 2D-DIGE and MALDI-TOF/TOF tandem mass spectrometry to profile the different proteins between xenograft models of the radiation group and $\beta$-elemene + radiation group. Prx-1 is a unique protein that was differentially expressed in the two treatment groups and downregulated in the combination group. Prx-1 has been found to be elevated in numerous types of cancers, including lung cancer (18-22). Several studies have demonstrated that Prx-1 is an independent prognostic factor and a novel plasma biomarker for lung cancer (23-25). In addition to being a novel tumor marker, Prx-1 was also found to be induced by radiation in various types of cancer cells in vitro $(26,27)$. Many cancer cells including lung cancer exhibited decreased growth and increased radiation response following suppression or knockdown of Prx-1 mRNA expression with RNA interference strategy (28-31). A549 cells also displayed increased radiosensitivity through enhanced intracellular reactive oxygen species (ROS) level following decreased Prx-1 protein expression with a targeted Prx-1 antibody (32). Our results acquired from 2D-DIGE and spectrometry revealed that $\beta$-elemene decreased the expression of Prx-1 to enhance the radioresponse in the A549 cell xenograft model.

We further tested the expression of Prx-1 in the radiation, $\beta$-elemene or combined treatment groups at the transcription and translation levels. Our results showed that radiation markedly induced the enhancement of Prx-1 expression, which was similar to the results of the studies mentioned above. As a major $\mathrm{H}_{2} \mathrm{O}_{2}$ scavenger and signaling regulator, elevated Prx-1 expression in post-radiated cancer cells can effectively reduce $\mathrm{H}_{2} \mathrm{O}_{2}$ levels induced by radiation, resulting in the enhanced survival of cancer cells.

In our previous study, we treated A549 cell xenografts with a 25,45 or $100 \mathrm{mg} / \mathrm{kg}$ dose of $\beta$-elemene followed by radiation. The enhancement factor (EF) following a dose of 25 , 
45 or $100 \mathrm{mg} / \mathrm{kg}$ dose was $0.84,1.24$ and 2.04 , respectively (9). Since a drug is considered to exhibit a synergistic effect with radiation only at a dose level where EF is $>1$ (33), this suggests that there was a synergistic effect when at least $45 \mathrm{mg} / \mathrm{kg}$ $\beta$-elemene was used with radiation therapy. This dose level was subsequently selected for later experiments including the present study. The $100 \mathrm{mg} / \mathrm{kg}$ dose level was not chosen in order to minimize the direct cytotoxic effect of $\beta$-elemene. In the present study, $\beta$-elemene alone at the dose of $45 \mathrm{mg} / \mathrm{kg}$ had little effect on the Prx-1 protein expression that was correlated with a moderate antitumor effect. However, the finding that the $45 \mathrm{mg} / \mathrm{kg}$ dose of $\beta$-elemene inhibited the Prx-1 mRNA expression suggests a possible influence at the level of transcription.

The finding that the increased radiation-induced Prx-1 mRNA/protein expression was significantly suppressed in the combination treatment group suggests that $\beta$-elemene directly or indirectly inhibited Prx-1 expression to enhance the radiosensitivity of the A549 cell xenograft model. Our previous study showed that $\beta$-elemene induced increased levels of ROS in A549 cells (34). Here, we suggest that the increasing ROS levels may be related to the inhibition of Prx- 1 expression by $\beta$-elemene. The mechanisms underlying the correlation between $\beta$-elemene and Prx-1 merit further investigation.

\section{References}

1. Parkin DM, Bray F, Ferlay J and Pisani P: Global cancer statistics, 2002. CA Cancer J Clin 55: 74-108, 2005.

2. Jiang $\mathrm{H}, \mathrm{Ma} \mathrm{S}$ and Feng $\mathrm{J}$ : In vitro study of radiosensitization by $\beta$-Elemene in A549 cell line from adenocarcinoma of lung. Chinese-German J Clin Oncol 8: 12-15, 2009.

3. Cheng W, Qiao Z, Shi T, Huang C and Wang Y: In vitro study on increase in radio sensitivity of renal cell carcinoma induced by $\beta$-Elemene. J Xi'an Jiaotong Univ: Med Sci (Chinese) 25 : $182-185,2004$

4. Wu D, Li X, Zhao J, Wang H and Zhao D: A study of radiosensitivity of $\beta$-elemene to squamous cell carcinoma of tongue Tca-8113 cell line in vitro. Zhong Liu Ji Chu Yu Lin Chuang 19: 116-117, 2006 (In Chinese).

5. She J, Wang Z, Che X and Pan C: Radiosensitization of $\beta$-elemene on VX2 carcinoma transplanted on kidney in rabbits in vivo. Zhong Xi Yi Jie He Xue Bao 4: 392-396, 2006.

6 . Wu DP, Jiang RB and Zhao DQ: Effects of $\beta$-elemene on radiosensitivity, cell cycle, apoptosis, Bcl2 and Bax expression of Tca8113 cells in vitro. Zheng Zou Da Xue Xue Bao 44: 414-417, 2009 (In Chinese)

7. She J, Wang $Z$ and Che $X$ : Expressions of caspase- 3 and Bcl-2 in radiosensitization of $\beta$-elemene on rabbit VX2 renal carcinoma. Zhong Xi Yi Jie He Xue Bao 27: 2285-2287, 2006 (In Chinese).

8. Li LJ, Zhong LF, Jiang LP, Geng CY and Zou LJ: $\beta$-Elemene radiosensitizes lung cancer A549 cells by enhancing DNA damage and inhibiting DNA repair. Phytother Res 25: 1095-1097, 2011.

9. Li G, Xie B,Li X, et al: Down-regulation of survivin and hypoxiainducible factor- $1 \alpha$ by $\beta$-elemene enhances the radiosensitivity of lung adenocarcinoma xenograft. Cancer Biother Radiopharm 27: 56-64, 2012

10. Wang T, Diaz AJ and Yen Y: The role of peroxiredoxin II in chemoresistance of breast cancer cells. Breast Cancer 6: 73-80, 2014.

11. Matés JM, Segura JA, Alonso FJ and Márquez J: Intracellular redox status and oxidative stress: implications for cell proliferation, apoptosis, and carcinogenesis. Arch Toxicol 82: 273-299, 2008.

12. Trachootham D, Alexandre J and Huang P: Targeting cancer cells by ROS-mediated mechanisms: a radical therapeutic approach? Nat Rev Drug Discov 8: 579-591, 2009.
13. Woo HA, Yim SH, Shin DH, Kang D, Yu DY and Rhee SG: Inactivation of peroxiredoxin I by phosphorylation allows localized $\mathrm{H}_{2} \mathrm{O}_{2}$ accumulation for cell signaling. Cell 140: 517-528, 2010.

14. Herbert BR, Harry JL, Packer NH, Gooley AA, Pedersen SK and Williams KL: What place for polyacrylamide in proteomics? Trends Biotechnol 19 (Suppl 10): S3-S9, 2001.

15. Tonge R, Shaw J, Middleton B, et al: Validation and development of fluorescence two-dimensional differential gel electrophoresis proteomics technology. Proteomics 1: 377-396, 2001.

16. Gharbi S, Gaffney P, Yang A, et al: Evaluation of two-dimensional differential gel electrophoresis for proteomic expression analysis of a model breast cancer cell system. Molecular Cell Proteomics 1: 91-98, 2002.

17. Yan JX, Devenish AT, Wait R, Stone T, Lewis S and Fowler S: Fluorescence two-dimensional difference gel electrophoresis and mass spectrometry based proteomic analysis of Escherichia coli. Proteomics 2: 1682-1698, 2002.

18. Chang JW, Jeon HB, Lee JH, et al: Augmented expression of peroxiredoxin I in lung cancer. Biochem Biophys Res Commun 289: 507-512, 2001.

19. Kim HJ, Chae HZ, Kim YJ, et al: Preferential elevation of Prx I and Trx expression in lung cancer cells following hypoxia and in human lung cancer tissues. Cell Biol Toxicol 19: 285-298, 2003.

20. Lehtonen ST, Svensk AM, Soini Y, et al: Peroxiredoxins, a novel protein family in lung cancer. Int J Cancer 111: 514-521, 2004.

21. Alfonso P, Catalá M, Rico-Morales ML, et al: Proteomic analysis of lung biopsies: differential protein expression profile between peritumoral and tumoral tissue. Proteomics 4: 442-447, 2004.

22. Park JH, Kim YS, Lee HL, et al: Expression of peroxiredoxin and thioredoxin in human lung cancer and paired normal lung. Respirology 11: 269-275, 2006.

23. Kim JH, Bogner PN, Ramnath N, Park Y, Yu J and Park YM: Elevated peroxiredoxin 1, but not NF-E2-related factor 2, is an independent prognostic factor for disease recurrence and reduced survival in stage I non-small cell lung cancer. Clin Cancer Res 13: 3875-3882, 2007.

24. Kim JH, Bogner PN, Baek SH, et al: Up-regulation of peroxiredoxin 1 in lung cancer and its implication as a prognostic and therapeutic target. Clin Cancer Res 14: 2326-2333, 2008.

25. Rostila A, Puustinen A, Toljamo T, et al: Peroxiredoxins and tropomyosins as plasma biomarkers for lung cancer and asbestos exposure. Lung Cancer 77: 450-459, 2012.

26. Chen WC, McBride WH, Iwamoto KS, et al: Induction of radioprotective peroxiredoxin-I by ionizing irradiation. J Neurosci Res 70: 794-798, 2002.

27. Zhang B, Su Y, Ai G, Wang Y, Wang T and Wang F: Involvement of peroxiredoxin $\mathrm{I}$ in protecting cells from radiation-induced death. J Radiat Res 46: 305-312, 2005.

28. Chen MF, Keng PC, Shau H, et al: Inhibition of lung tumor growth and augmentation of radiosensitivity by decreasing peroxiredoxin I expression. Int J Radiat Oncol Biol Phys 64: 581-591, 2006.

29. Zhang B, Wang Y, Liu K, et al: Adenovirus-mediated transfer of siRNA against peroxiredoxin I enhances the radiosensitivity of human intestinal cancer. Biochem Pharmacol 75: 660-667, 2008.

30. Gao MC, Jia XD, Wu QF, Cheng Y, Chen FR and Zhang J: Silencing Prx1 and/or Prx 5 sensitizes human esophageal cancer cells to ionizing radiation and increases apoptosis via intracellular ROS accumulation. Acta Pharmacol Sin 32: 528-536, 2011.

31. Dittmann LM, Danner A, Gronych J, et al: Downregulation of PRDX1 by promoter hypermethylation is frequent in $1 \mathrm{p} / 19 \mathrm{q}$-deleted oligodendroglial tumours and increases radio- and chemosensitivity of Hs683 glioma cells in vitro. Oncogene 31: 3409-3418, 2012

32. Guo Q, Huang X, Zhang J, Luo Y, Peng Z and Li S: Downregulation of peroxiredoxin $I$ by a novel fully human phage display recombinant antibody induces apoptosis and enhances radiation sensitization in A549 lung carcinoma cells. Cancer Biother Radiopharm 27: 307-316, 2012.

33. Milas L, Fujii T, Hunter N, et al: Enhancement of tumor radioresponse in vivo by gemcitabine. Cancer Res 59: 107-114, 1999.

34. Li LJ, Zhong LF, Jiang LP, et al: Lysosomal membrane permeabilization contributes to elemene emulsion-induced apoptosis in A549 cells. Free Radic Res 45: 1232-1240, 2011. 